\title{
FLOW BOILING OF WATER IN A SQUARE METALLIC MICROCHANNEL
}

\author{
S.Korniliou*and T. G. Karayiannis \\ Department of Mechanical and Aerospace Engineering, Brunel University London, Uxbridge UB8 3PH, UK
}

\section{INTRODUCTION}

Recent advancements in the electronics industry led to smaller and more powerful systems. Therefore, efficient heat dissipation for cooling of microelectronics systems, integrated circuit chips, power semiconductor devices such as IGBTs and laser diodes is required. In such systems, heat fluxes in the order of $\mathrm{MW} / \mathrm{m}^{2}$ need to be removed from small spaces, while maintaining the temperature below a certain design limit [1]. Flow boiling in microchannels is one of the most promising methods for achieving these high cooling demands because it can dissipate large heat fluxes over a small surface area by utilizing the latent heat of the coolant [2]. Literature review indicates that there are still disagreements on the prevailing flow patterns, heat transfer rates and pressure drop trends, see Mahmoud and Karayiannis [3]. The main objective of the present work was to investigate the flow boiling flow patterns, heat transfer coefficient and pressure drop characteristics in a square metallic microchannel at different inlet subcooling, mass flux and heat flux conditions, using water as the working fluid.

\section{METHODOLOGY}

The experimental facility consists of a reservoir, a sub-cooler, a magnetic drive gear pump, a Coriolis flow meter, a preheater, an inline filter of $90 \mu \mathrm{m}$ placed after the preheater, a sight glass, test section, a glycol-water circulation chiller and a reflux condenser. After degassing in the reservoir, DI water was circulated in the flow loop system at the desired flow rate and inlet temperature. System pressure was maintained constant at 1 bar by controlling the reservoir temperature. A single rectangular microchannel $1 \mathrm{~mm}$ high, $1 \mathrm{~mm}$ wide and $75 \mathrm{~mm}$ long was cut in the top surface of a copper block using a high-speed micro-milling machine (Kern HSPC 2216), see Fig. 1 (a). The average surface roughness $(R a)$ of the microchannel was found to be $0.252 \pm 0.08 \mu \mathrm{m}$. The average was produced from five locations equally spaced along the channel. The inlet and outlet plenums of the test section were fabricated in polycarbonate in order to reduce the heat transfer losses. Seven K-Type thermocouples (accuracy of $\pm 0.12 \mathrm{~K}$ ) were inserted into the copper block at a distance of $0.7 \mathrm{~mm}$ below the channel bottom to obtain surface temperatures along the channel. The thermocouple locations are depicted in Fig. 1 (b). Readings from thermocouples T4 and T9T13 where used to evaluate the heat flux distribution in the copper block. Two cartridge heaters (total power of 800 W) were placed horizontally, parallel to the channel inside the copper block. An acrylic transparent plate on the top was supported in place with the copper block by an aluminum cover and bottom plate. The inlet pressure was measured at the inlet plenum using an absolute pressure transducer. The pressure drop between the microchannel inlet and outlet was measured using a differential pressure transducer. Inlet and outlet liquid temperatures were measured using two K-type thermocouples. The camera used to obtain the flow patterns was a High-Speed MicroLAB110 Phantom. The flow patterns were obtained at a frame rate of 4,609 fps and resolution of $768 \times 480$. Flow visualisation was carried out at the inlet, middle and outlet of the microchannel. The flow boiling experiments were carried out at different subcooling conditions of $\Delta T_{\text {sub }}=5,15$ and $50 \mathrm{~K}$ for heat fluxes between 200-1,130 $\mathrm{kW} / \mathrm{m}^{2}$ at three constant mass fluxes of 200,400 and $600 \mathrm{~kg} / \mathrm{m}^{2} \mathrm{~s}$ and inlet pressure of 1 bar. The experimental setup was validated with single-phase experiments. The relationships for the theoretical friction factor for fully developed and developing flow given by Shah [5] predicted the experimental friction factor data well for all test sections with a Mean Absolute Error (MAE) of 2.8-14.5 \%. The single-phase Nusselt number in the test section was predicted well with the correlation of Choi et al. [6], for the range of $200-1580 \mathrm{~kg} / \mathrm{m}^{2} \mathrm{~s}$ and for $R e<2000$, i.e. MAE of 2.03$8.50 \%$. 

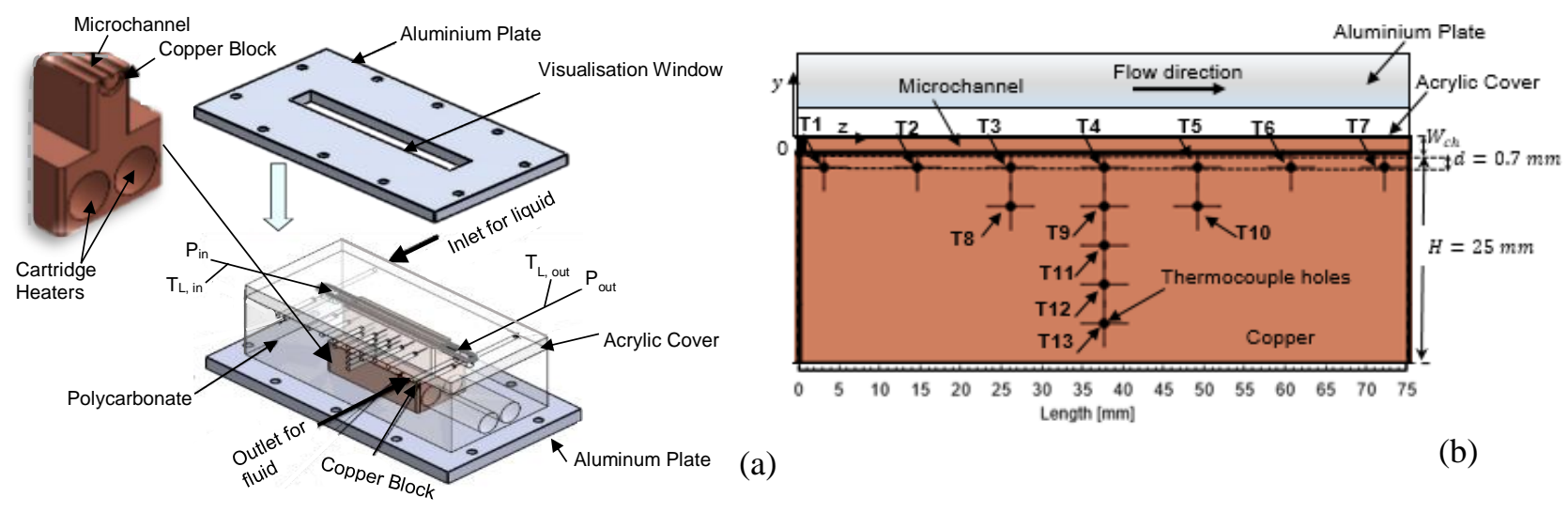

(a)

(b)

Fig. 1 (a) Test section assembly depicting the two aluminium plates, the copper block with microchannel, the polycarbonate block and acrylic cover and (b) thermocouples along the channel and copper block.

\section{RESULTS}

The flow patterns observed in this study where bubbly, confined bubble, slug, churn and annular flow. Churn flow was observed to occur only at a very small section of the channel or not observed at all in some cases due to fast transition from bubbly and slug to the annular flow regime, which is usually observed to occur only in small tubes [3] and fluids like water. Fig. 2 shows the observed flow patterns along the entire channel length for the medium mass flux values of $G=400 \mathrm{~kg} / \mathrm{m}^{2} \mathrm{~s}$ at a constant heat flux of $q "=380 \mathrm{~kW} / \mathrm{m}^{2}$ and inlet subcooling of $\Delta T_{\text {sub }}=5 \mathrm{~K}$. (Vertical lines indicate different photos that were put together.) The flow patterns changed along the channel as a result of channel confinement, bubble coalescence and increasing vapour quality. Fig. 2 shows that for these conditions, single phase occurred at the first $2 \mathrm{~mm}$ and bubbly flow occurred at the next $4 \mathrm{~mm}$ of the channel. This was followed by confined bubble-slug flow at the next $10 \mathrm{~mm}$, churn flow $(\sim 5 \mathrm{~mm})$ and then annular flow, which occupied a big section of the channel length $(\sim 47 \mathrm{~mm})$.

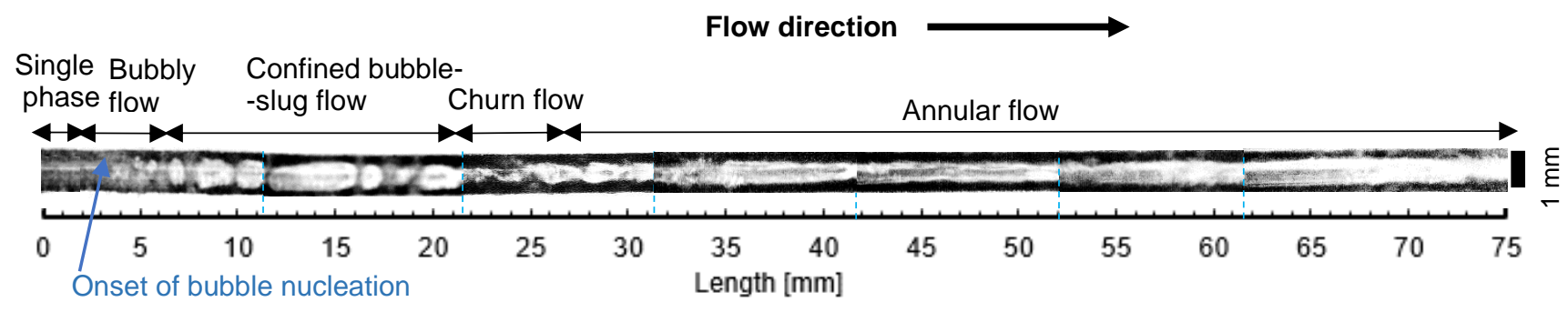

Fig. 2 Flow patterns along the microchannel length for the mass flux of $G=400 \mathrm{~kg} / \mathrm{m}^{2} \mathrm{~s}$, inlet subcooling of $\Delta T_{\text {sub }}=$ $5 \mathrm{~K}$ and heat flux of $q "=380 \mathrm{~kW} / \mathrm{m}^{2}$.

As expected, increasing the inlet subcooling, resulted in increasing entry length (single-phase). The annular flow regime was established almost along the whole channel length for low degree of subcooling $\left(\Delta T_{\text {sub }}=5,15 \mathrm{~K}\right)$. For low mass flux of $G=200 \mathrm{~kg} / \mathrm{m}^{2} \mathrm{~s}$ at $\Delta T_{\text {sub }}=5 \mathrm{~K}$, periodic flow reversal was observed to occur, which was caused by bubbles that expanded both upstream and downstream. It is worth mentioning that bubble nucleation was observed to occur in the liquid thin film during the annular flow regime for all mass fluxes with increasing heat flux. Fig 3 shows part of the channel where bubble nucleation in the thin film occurred for the conditions of $G=$ $600 \mathrm{~kg} / \mathrm{m}^{2} \mathrm{~s}, q^{\prime \prime}=680 \mathrm{~kW} / \mathrm{m}^{2}$ and $\Delta T_{\text {sub }}=50 \mathrm{~K}$. This is in agreement with a recent study by Ali et al.[5], where nucleating bubbles were visualized in the liquid film in the slug and annular flow regime with increasing heat flux in rectangular multi-channels of $0.46 \mathrm{~mm}$ hydraulic diameter using HFE-7100. As the heat flux increased and with the thinning of the liquid film, bubbles disappeared. 
Thinning of the liquid film was observed to occur along the channel length during the annular flow regime that can cause local dryout at high heat fluxes $\left(q^{\prime \prime}>680 \mathrm{~kW} / \mathrm{m}^{2}\right)$. Local dryout can account for reduced heat transfer coefficient as vapour quality increases with channel length.

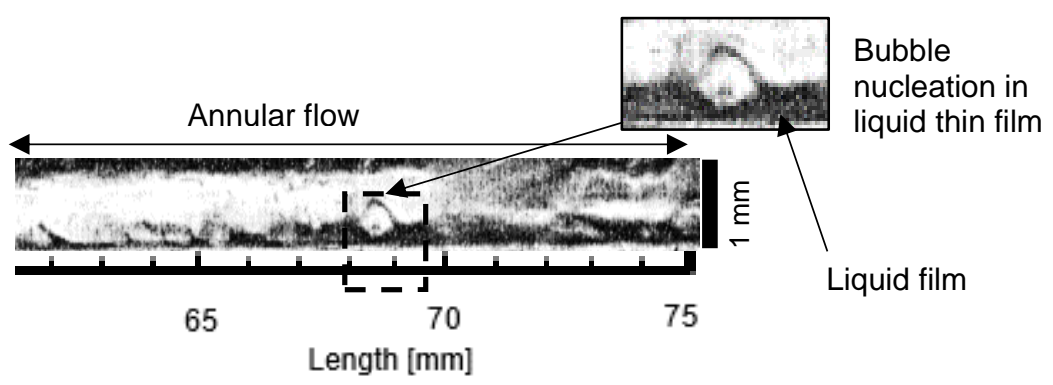

Fig. 3 Annular flow with bubble nucleation in thin liquid film observed at $G=600 \mathrm{~kg} / \mathrm{m}^{2} \mathrm{~s}$, inlet subcooling of $\Delta T_{\text {sub }}=$ $5 \mathrm{~K}$ and heat flux of $q "=680 \mathrm{~kW} / \mathrm{m}^{2}$.

\section{CONCLUSIONS}

Flow boiling experiments were carried out in a copper microchannel test section having $1 \mathrm{~mm}$ hydraulic diameter. Flow patterns were recorded along the whole channel length for mass flux from 200 to $600 \mathrm{~kg} / \mathrm{m}^{2} \mathrm{~s}$ and a pressure of $1 \mathrm{bar}$ for three different inlet degree of subcooling, namely $5 \mathrm{~K}, 15 \mathrm{~K}$, and $50 \mathrm{~K}$ and heat fluxes up to 1,130 $\mathrm{kW} / \mathrm{m}^{2}$. Bubbly, confined bubble flow-slug flow, churn flow and annular flow were observed to occur in the channel. Churn flow occurred for a very short length of the channel due to early transition to annular flow. Annular flow with bubble nucleation in thin liquid film was observed to occur for all mass fluxes. This was not sustained at high heat fluxes where the liquid film was very thin.

A detailed comparison of the flow regimes observed in this study with flow pattern maps presented in the literature, e.g. see [6] will be presented. The effect of inlet subcooling, heat flux and mass flux on two-phase pressure drop and local and average two-phase heat transfer coefficient will be also presented. In addition, heat transfer rates and pressure drop results will be compared with correlations available in the literature and presented at the meeting.

\section{REFERENCES}

[1] T. G. Karayiannis and M. M. Mahmoud, "Flow boiling in microchannels: Fundamentals and applications," Appl. Therm. Eng., vol. 115, pp. 1372-1397, 2017.

[2] S. Wang et al., "Cooling design and evaluation for photovoltaic cells within constrained space in a CPV/CSP hybrid solar system," Appl. Therm. Eng., vol. 110, pp. 369-381, 2017.

[3] M. M. M. and T. G. Karayiannis, "Chapter 4: Flow Boiling in Mini to Microdiameter Channels," in Encyclopedia of TwoPhase Heat Transfer and Flow IV, 2018, pp. 233-301.

[4] R. K. Shah and D. P. Drop, "Correlation for laminar hydrodynamic entry length solutions for circular and non-circilar ducts," J. Fluids Enginnering, 1978.

[5] A.H. Al-Zaidi, M.M.Mahmood, T.G. Karayiannis, "Flow boiling of HFE-7100 in Multi-Microchannels: Aspect Ratio Effect", 6th Int. Micro and Nano Flows Conference, Atlanta, 2018.

[6] M. M. Mahmoud and T. G. Karayiannis, "Flow pattern transition models and correlations for flow boiling in mini-tubes," Exp. Therm. Fluid Sci., pp. 270-282, 2016. 